\title{
Overhauling Implant Thread Exposure: A Case Report
}

\author{
${ }^{1}$ Eswaran B, ${ }^{2}$ Rathika Rai, ${ }^{3}$ Rahul Singh
}

\begin{abstract}
Dental implants are considered to be one of the most successful forms of prosthetic rehabilitation for both partial and completely edentulous patients. The pros and cons of prosthetic dental implants are attributed to the necessity of technique sensitivity. One of the most common challenges faced during prosthetic dental implant placement is soft tissue management, particularly in the lower posterior partial/ completely edentulous regions. Several factors such as excessive loading of the implant, localized periodontal infection or presence of frenal or muscular pull may lead to exposure of the dental implant threads. With the prevailing dental implant, treatment challenges may occur one of them is implant thread exposure which might require unconventional treatment option because the exposed thread in osseointegrated implant are difficult to clean may not be amenable to regenerative therapy. Following case report elaborates exposure of the threads of dental implants as a result of excessive muscle traction after stage one of implant placement and a successful minor corrective surgical technique was used to correct the aforementioned etiology.
\end{abstract}

Keywords: Implant, Implant thread, Thread exposure, Vestibuloplasty.

How to cite this article: Eswaran B, Rai R, Singh R. Overhauling Implant Thread Exposure: A Case Report. Int J Oral Implantol Clin Res 2017;8(2\&3):61-64.

Source of support: Nil

Conflict of interest: None

\section{INTRODUCTION}

Dental implants are considered to be one of the most successful forms of prosthetic rehabilitation for both partial and completely edentulous patients. The pros and cons of prosthetic dental implants are attributed to the necessity of technique sensitivity and increasing demands of patient's oral hygiene. ${ }^{1}$

By definition total failure of a prosthetic dental implant can be associated with a substantial decrease in mechanical, biological and functional purposes. Truhlar Reiter syndrome has classified dental implants based on

\footnotetext{
${ }^{1}$ Postgraduate Student, ${ }^{2}$ Reader, ${ }^{3}$ Principal and HOD

${ }^{1-3}$ Department of Prosthodontics, Thai Moogambigai Dental College and Hospital, Chennai, Tamil Nadu, India

Corresponding Author: Rahul Singh, Principal and HOD, Department of Prosthodontics, Thai Moogambigai Dental College and Hospital, Chennai, Tamil Nadu, India, e-mail: rahulrajpurohit28@gmail.com
}

improper technique during placement of implants, disregard for maintenance of oral hygiene and any associated systemic diseases. $^{2}$

One of the most common challenges faced during prosthetic dental implant placement is soft tissue management, particularly in the lower posterior partial/ completely edentulous regions. Several factors such as excessive loading of the implant, localized periodontal infection or presence of frenal or muscular pull may lead to exposure of the dental implant threads. ${ }^{3}$

Following case report elaborates exposure of the threads of dental implants as a result of excessive muscle traction after stage one of implant placement and a successful minor corrective surgical technique was used to correct the aforementioned etiology.

\section{CASE DISCUSSION}

A 38-year-old female reported in the department of prosthodontics for replacement of her right lower back missing teeth, on examination missing 46 and 47 were found. The patient had no known history of medical illness and was planned for implant in relation to 46 and 47 regions (Fig. 1). A preoperative diagnostic impression was made, Orthopantomogram (OPG) (Fig. 2) and complete blood picture was prescribed.

The diagnostic cast was made and bone mapping was done and implant diameter of $4.5 \times 12 \mathrm{~mm}$ at 46 regions and $4.5 \times 9 \mathrm{~mm}$ was selected for 47 regions. On the day of surgery inferior alveolar nerve block was given followed by mid crestal incision and the vertical relieving incision was given initial lancet/pilot drill was done followed by sequential osteotomy, implants were placed and primary stability was achieved. A cover screw was placed, and the

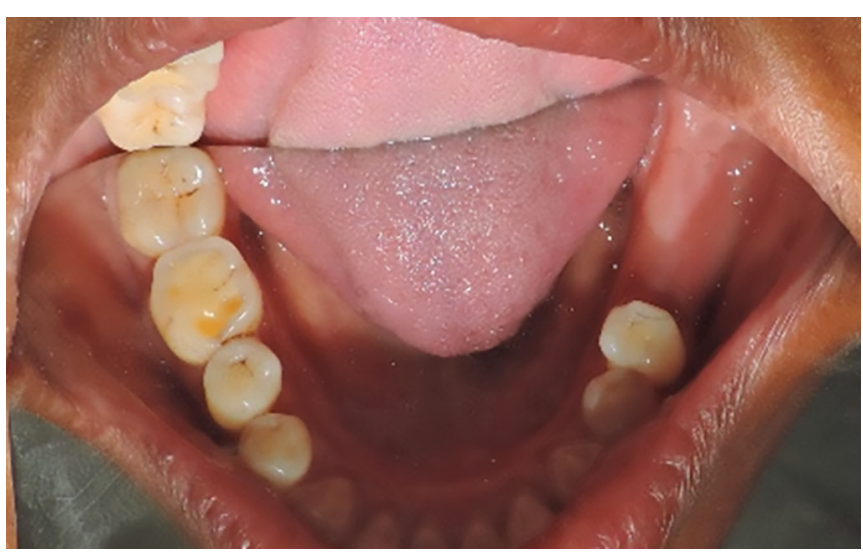

Fig. 1: Preopretive photograph missing teeth 46 and 47 region 
site was closed with braided silk non-absorbable sutures with three simple interrupted suture technique. Postoperative radiographs (Fig. 3) were taken and the patient was prescribed appropriate analgesics and antibiotics.

On the third day after the procedure patient complained of pain on examination two sutures were missing one suture was tagged along with the free end of the flap. implant site was exposed with visibility of two threads buccally. Wound site was irrigated with $0.2 \%$ chlorhexidine and Alloplastic graft was placed near the exposed threads then the wound was sutured back, the patient was advised to maintain oral hygiene. The patient was reviewed after 7 days, and the wound site was not approximated with graft material washed away (Fig. 4). The wound was left for primary healing and the patient was recalled after 2 weeks. On next recall patient had no pain or discomfort in the implant region and examination wound was healed and there was a thread exposure buccally (Fig. 5).

On examination blanching of tissue around the implant was seen with slight pull with and interdisciplinary advice was sought. It was confirmed that the site was not able to approximate due to buccal traction

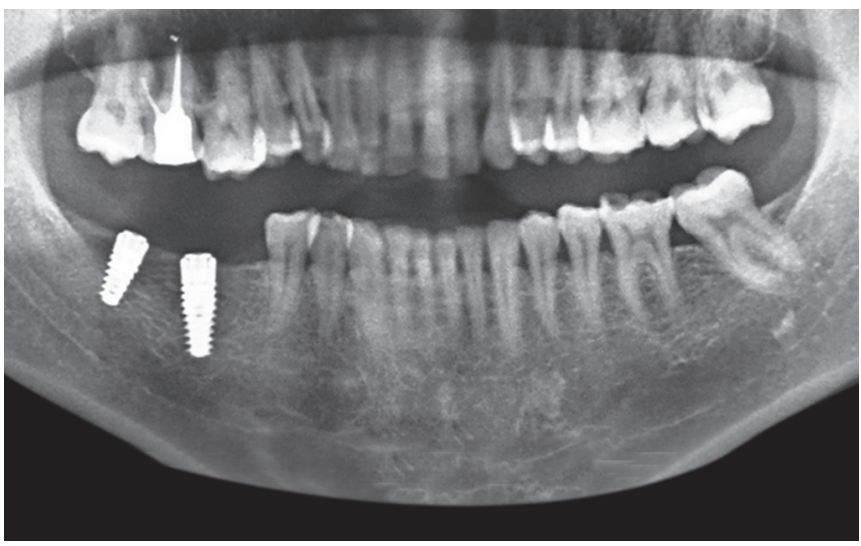

Fig. 2: Postoperative OPG showing implant in 46 and 47 regions

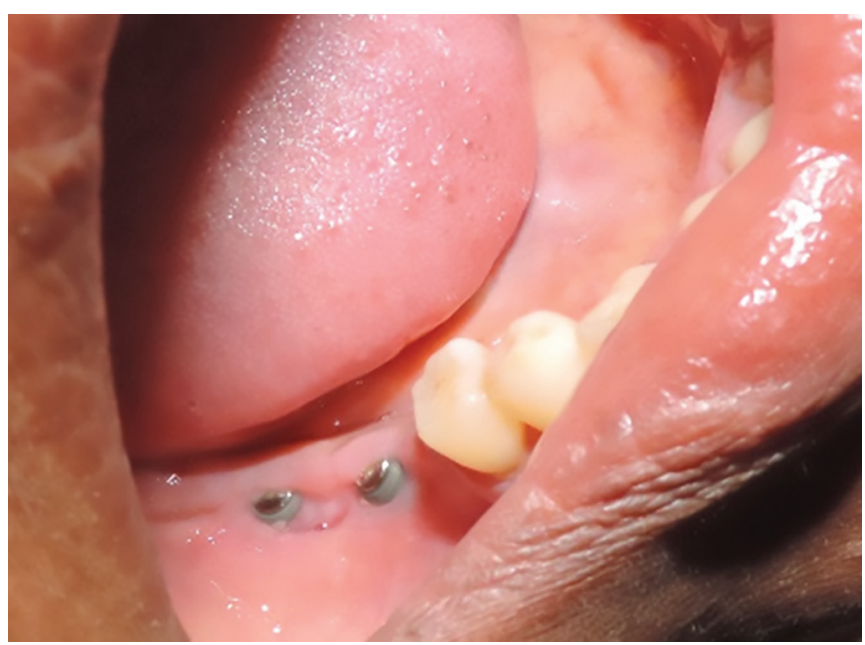

Fig. 4: Implant picture one-month postoperative, left intentional healing showing exposed thread in buccal regions from muscle and fibers of muscle attached to the flap this would further cause recession of buccal mucosa further exposing the thread, so a vestibuloplasty procedure was advised to relieve the mucosa from further traction by the muscles. Anatomically this area has close proximity to buccinator muscle and pterygomandibular raphe.

\section{Vestibuloplasty}

Inferior alveolar nerve block was given followed by a deep sulcular incision in the buccal sulcus of 46 and 47 regions (Fig. 6), fibers of muscle were detached from mucoperiosteum free flap end sutures were given to avoid muscle attachment to the periosteum (Fig. 7), and healing screw was placed. Eugenol-free, the surgical dressing was given for 2 weeks (Fig. 8). After two weeks' eugenolfree, the surgical dressing was removed and the site was examined for healing (Fig. 9). Again patient was recalled for review after one month and on examination, there was complete colure of the exposed thread was found without any uneventful complication (Figs 10 and 11). Further prosthetic phase was advised.

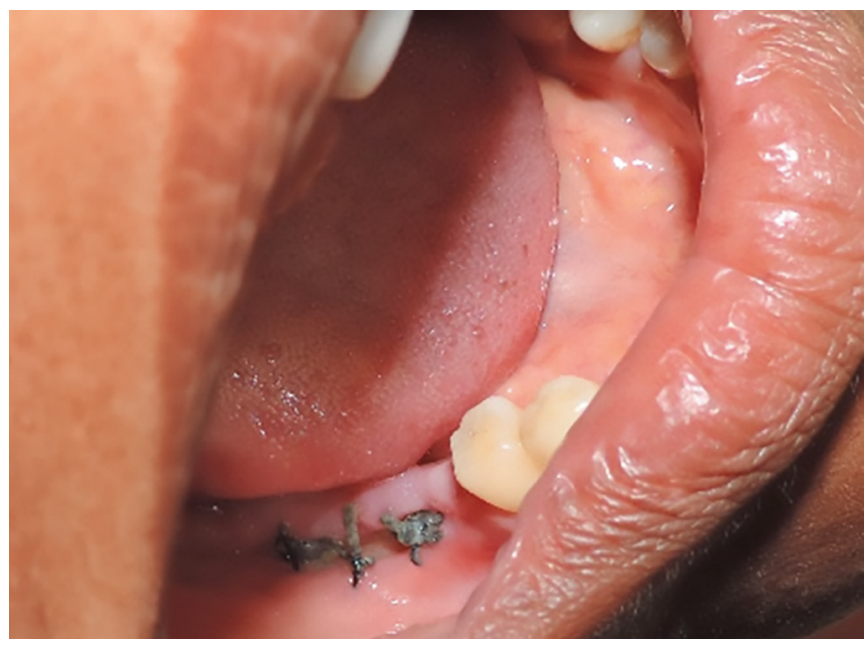

Fig. 3: 14 days' postoperative picture taken after some time resuturing the site showing incomplete closure of site

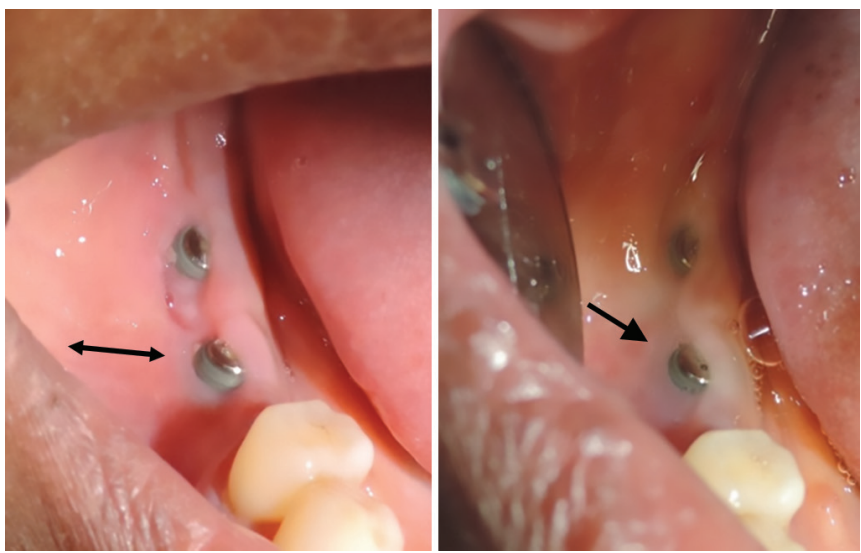

Fig. 5: Blanching of tissue around the implants 


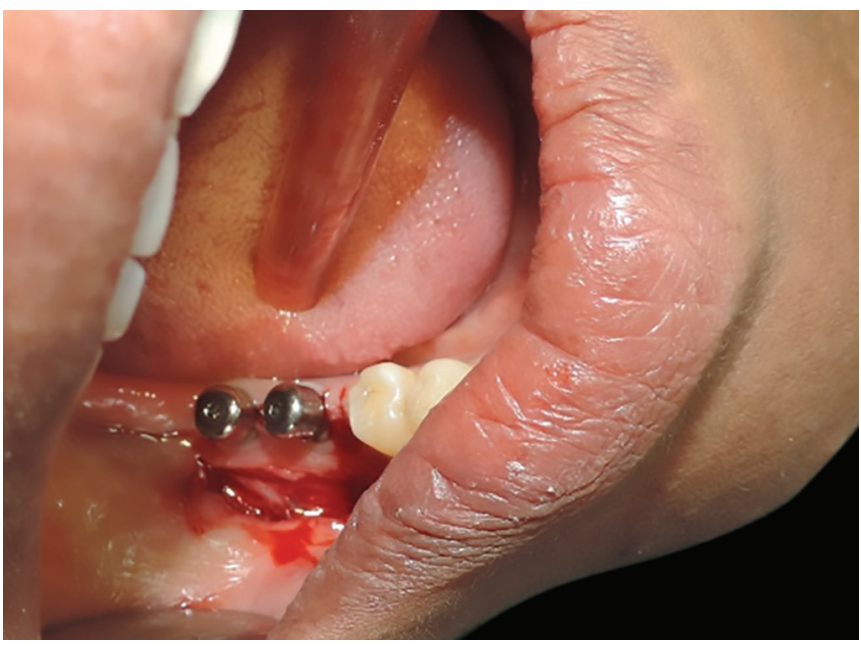

Fig. 6: Sulcular incision in the buccal sulcus of 46 and 47 regions

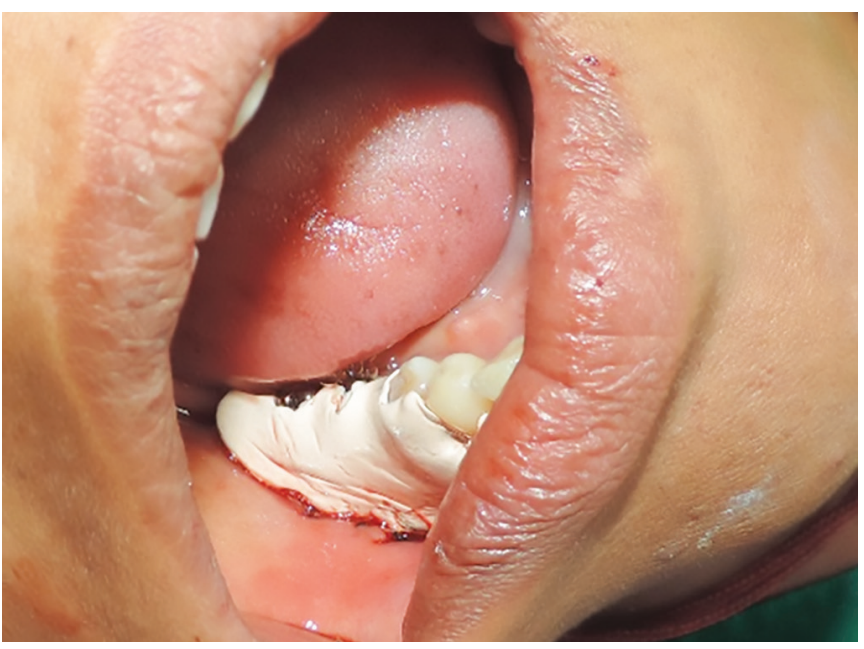

Fig. 8: Sulcular incision in the buccal sulcus of 46 and 47 regions

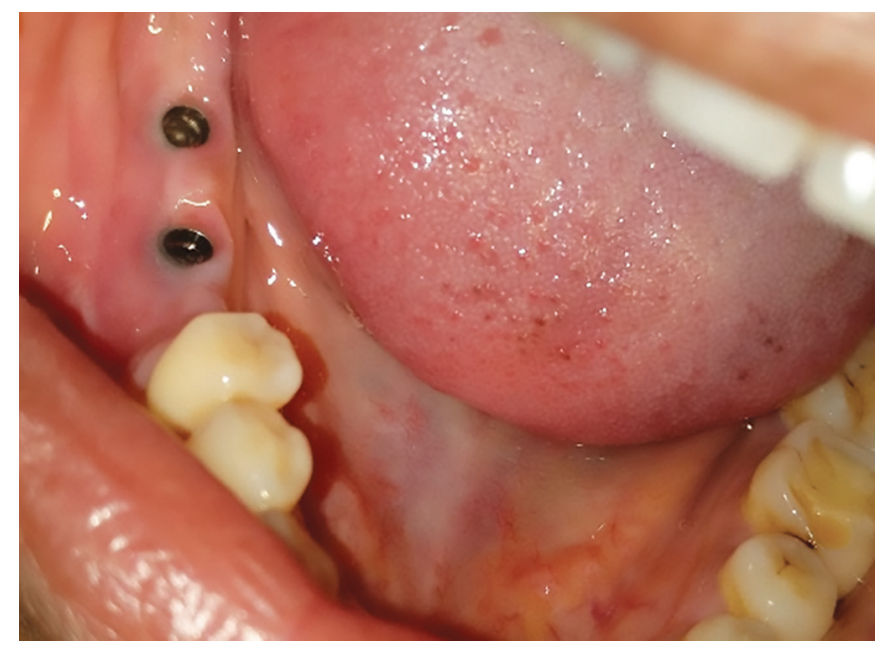

Fig. 10: Healed soft tissue around implants

\section{DISCUSSION}

Soft tissue plays an important role in framing the implant prosthesis failure to achieve is categorized as soft tissue insuffieciancy ${ }^{4}$ or biological failure in this case due to the

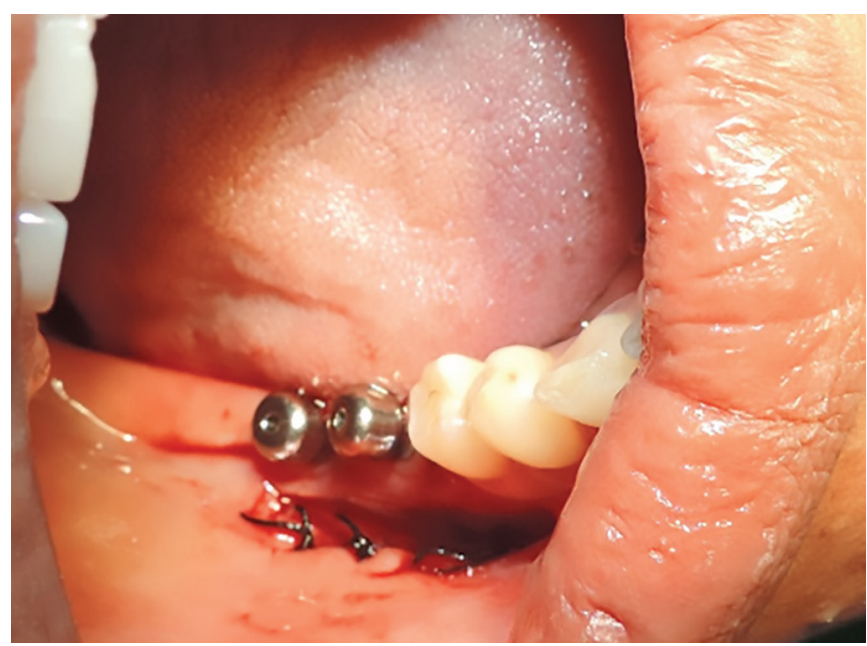

Fig. 7: Free flap end sutures were given to avoid muscle attachment to the periosteum

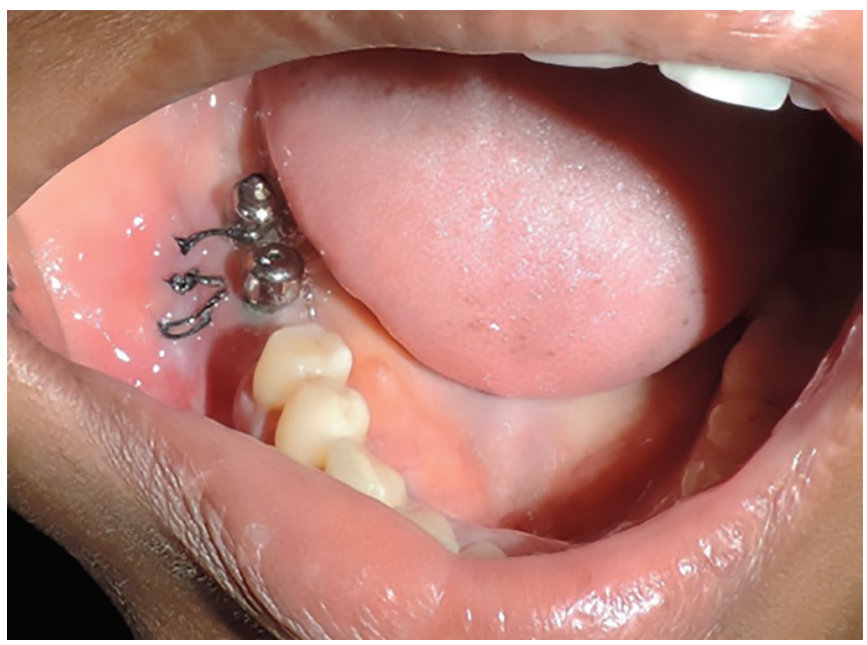

Fig. 9: Healing of sulcus after vestibuloplasty

apical recession of soft issue caused by buccal traction from buccinator and pterygomandibular raphe attached to mucoperiosteum. These soft tissue insufficiencies in the anterior region will cause aesthetic issues and will compromise oral hygiene in posterior region. ${ }^{5}$

Several authors have given many techniques in increasing soft tissue volume around the implant ${ }^{6-8}$ but without knowing the etiology correction may also fail. Soft tissue has many factors which may be due to habits such as smoking, parafunctional habits local factors such as poor oral hygiene, poor prosthesis delivery, poor wound healing after placement of the implant and biological factor such has mucosal biotype and its attachment to the underlying periosteum. ${ }^{9}$

The underlying cause of the soft tissue insufficiency should be managed before the corrective procedure is done, in this case, the cause of the recession of soft tissue after implant placement was from the muscle traction causing soft tissue defect. Etiology was identified and corrected further improving the integrity of the implant. Further 

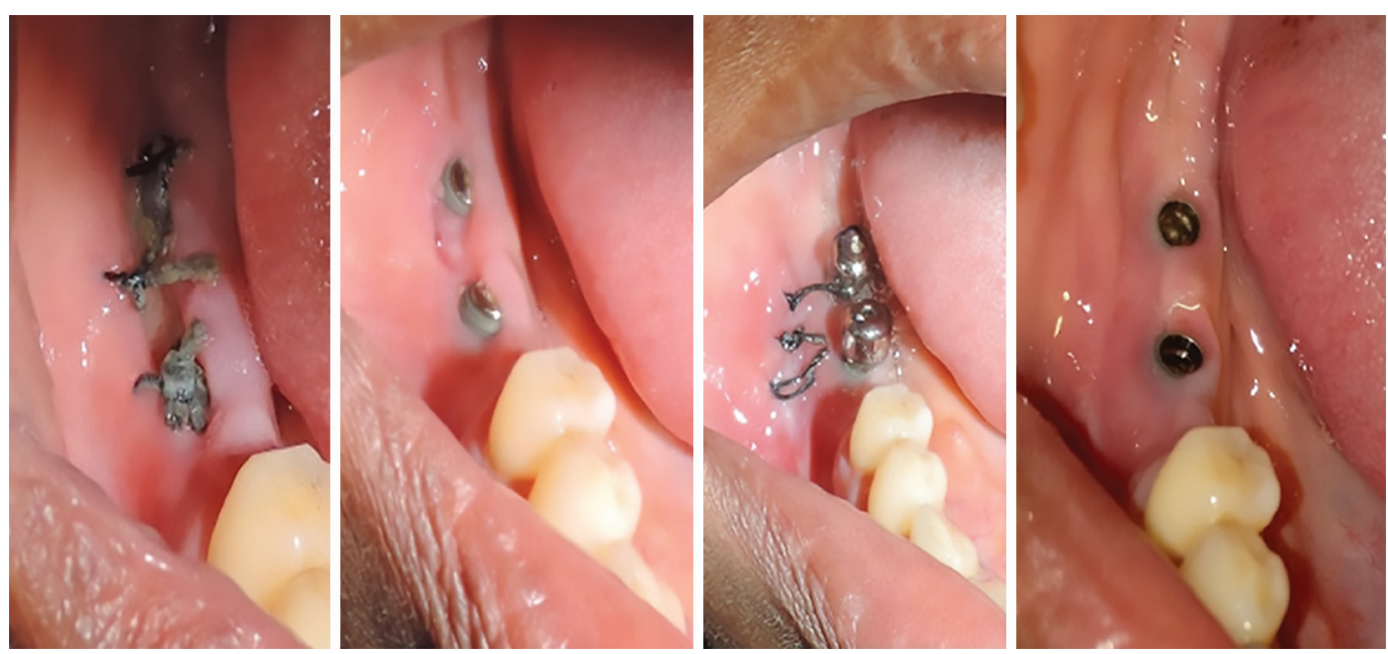

Fig. 11: Sequence of healing of soft tissue around implants after initial thread exposure

these type cases soft tissue should be analyzed and planned before surgical stage such as whether to raise full thickness flap or a flapless surgery which avoids elevation of mucoperiosteum thus avoiding pull from the muscles. ${ }^{10}$ guides are there which are simple to fabricate can be used to locate the implant site after the first stage avoiding elevation of flaps and easily locating the implant site further avoiding this type of complications. ${ }^{11}$

\section{CONCLUSION}

Local soft tissue complication arising after implant placements may not be causing failure but, may land up as an etiologic cause for failure. There may be persistent inflammation due to impaired hygiene and accumulation of plaque on exposed implant threads. The soft tissue should be well analyzed clinically and functionally, equal importance to be given to soft tissue similar to the bone which is analyzed radiographically to avoid future complication. Priority should be the prevention of such complication. Correction without removing the etiology will cause a relapse of the situation if any complication arises the main goal should be finding the causative factor rather than proceeding to the corrective phase.

\section{REFERENCES}

1. El Askary AS, Meffert RM, Griffin T. Why do dental implants fail? Part I. Implant dentistry. 1999 Jan 1;8(2):173-185.
2. Truhlar RS. Perimplantitis - Causes and treatment. Oral Maxillofac Surg Clin North Am 1998;10:299-308.

3. Claffey N, Clarke E, Polyzois I, Renvert S. Surgical treatment of peri-implantitis. J Clin Periodontol 2008;35:316-332.

4. Esposito M, Hirsch JM, Lekholm U, Thomsen P. Biological factors contributing to failures of osseointegrated oral implants,(I). Success criteria and epidemiology. European journal of oral sciences. 1998 Feb;106(1):527-551.

5. Chee W, Jivraj S. Failures in implant dentistry. British dental journal. $2007 \mathrm{Feb} ; 202(3): 123$.

6. El Askary AS. Use of connective tissue grafts to enhance the esthetic outcome of implant treatment: a clinical report of 2 patients. The Journal of prosthetic dentistry. $2002 \mathrm{Feb}$ 1;87(2):129-132.

7. Price RB, Price DE. Esthetic restoration of a single-tooth dental implant using a subepithelial connective tissue graft: a case report with 3-year follow-up. International Journal of Periodontics \& Restorative Dentistry. 1999 Feb 1;19(1):92-101.

8. Goldstein AR. Soft tissue ridge augmentation to correct an esthetic deformity caused by adversely placed implants: a case report. International Journal of Periodontics \& Restorative Dentistry. 1998 Jun 1;18(3)287-291.

9. Annibali S, Ripari M, La Monaca G, Tonoli F, Cristalli MP. Local complications in dental implant surgery: prevention and treatment. ORAL \& implantology. 2008 Apr;1(1):21.

10. Romero-Ruiz MM, Mosquera-Perez R, Gutierrez-Perez JL, Torres-Lagares D. Flapless implant surgery: A review of the literature and 3 case reports. Journal of clinical and experimental dentistry. 2015 Feb;7(1):e146.

11. Baskaran E, Thillaigovindan R, Radhakrishnan P,Arumugam E. Implant location made simple-A novel technique using multifaceted RPD-A case report. IJBR. 2016 Nov 1;7(10): 751-753. 